\title{
Continuous Medical Education in Obstetrics and Gynecology Ultrasound: Asian Experience
}

${ }^{1-3}$ Ritsuko K Pooh

\begin{abstract}
Ultrasound is the most commonly used diagnostic modality in Obstetrics and Gynecology. However, sonographic imaging is greatly influenced by individual technique and knowledge rather than ultrasound equipment. Ultrasound imaging requires not only basic knowledge of anatomy, physiology, reproductive medicine and imaging interpretation, but also scanning skills. In Japan, two types of lan Donald courses have been held: basic and advanced courses. Live scan demonstration and hands-on sessions have been introduced in 2006. From 2006, China, Indonesia, Hong Kong, Philippines, Vietnam, Korea and Thailand established lan Donald branches one after another. lan Donald Inter-university School of Medical Ultrasound provides the most comprehensive, practical and systematic theoretical/ practical courses. For better efficacy, distance learning should be implemented.
\end{abstract}

Keywords: Ultrasound education, Ultrasound, Ian Donald Asia, Japan.

How to cite this article: Pooh RK. Continuous Medical Education in Obstetrics and Gynecology Ultrasound: Asian Experience. Donald School J Ultrasound Obstet Gynecol 2014;8(1):65-71.

\section{Source of support: Nil}

Conflict of interest: None

\section{INTRODUCTION}

Education in its general sense is a form of learning in which the knowledge, skills and habits of a group of people are transferred from one generation to the next through teaching, training or research. Education frequently takes place under the guidance of others, but may also be autodidactic. Learning means change, new modes of behavior, new structures, unfamiliar situations and creativity. The increased speed at which we have to acquire new knowledge, insights and

${ }^{1}$ Director, ${ }^{2}$ Professor, ${ }^{3}$ Executive Director

${ }^{1}$ CRIFM Clinical Research Institute of Fetal Medicine and PMC Osaka, Japan

${ }^{2}$ Department of Human Sciences, Dubrovnik International University, Dubrovnik, Croatia

${ }^{3}$ Asian Regional Director, Japanese Branch Director, lan Donald Inter-University School of Medical Ultrasound

Corresponding Author: Ritsuko K Pooh, CRIFM Clinical Research Institute of Fetal Medicine and PMC, 7-3-7, Uehommachi Tennoji, Osaka \#543-0001, Japan, Phone: +81-667758111 Fax: +81-667758122, e-mail: rkpooh@me.com abilities is forcing us to divide learning into novel, shorter phases. The traditional choreography of learning with its long, rigidly defined school, job and university educational periods is already obsolete. Self-organized, lifelong learning is becoming a necessity. Education is needed more than ever to give the individual the proper orientation to make good judgments. Only on this basis, one can think and act selfsufficiently, self-confidently and self-effectively.

Ultrasound is most commonly used diagnostic modality in obstetrics and gynecology. However, sonographic imaging is greatly influenced by individual technique and knowledge rather than ultrasound equipment. Ultrasound imaging requires not only basic knowledge of anatomy, physiology, reproductive medicine, imaging interpretation but also scanning skills. School lectures, published articles and the use of technology, such as online education, a type of distance learning, can efficiently teach basic knowledge. To learn and obtain scanning technique, however, is difficult through lectures, articles or even online education, and it needs direct education by live-scanning demonstration and hands-on training.

Ian Donald Inter-University School of Medical Ultrasound has developed a systematic ultrasound education, including both basic theoretical and practical education. Japan branch introduced first Ian Donald course in 1998. In Asian region, the number of Ian Donald branches has increased, and numerous enthusiastic/sophisticated educational courses have been completed.

\section{ULTRASOUND EDUCATION IN OBSTETRICS AND GYNECOLOGY}

Obstetrics and gynecology imaging includes magnetic resonance imaging (MRI) and three-dimensional computed tomography (3D-CT) as well as ultrasound. Magnetic resonance imaging and $\mathrm{CT}$ require capacity of postimaging radiographic image interpretation. Ultrasound examination is, however, completely different from other imaging modalities in terms of real-time imaging and interpretation. Examiners are requested to have both interpretation capacity and scanning expertise simultaneously based on physiological and pathological knowledge of reproductive and maternal fetal medicine. Therefore, ultrasound examination needs appropriate and thorough education and training. Fetal 
ultrasound education/training, however, is not systematic and very few successful educational programs are provided. It is not easy to develop ultrasound education curriculum, because ultrasound education should include case examples, video cases, interactive tutorials, online ultrasound simulation, on-site attendance necessary for practical experience, on-site ultrasound simulation and hands-on training of real patients. Comprehensive ultrasound training includes observation and shadowing of the ultrasound experts. It is not similar to education in other imaging techniques, such as MRI and CT, which predominantly include interpretation skills. Ultrasound is dependent on examiners' skill as well as quality of interpretation. It is equally important how to scan, how to detect and how to demonstrate the most objective and informative images.

\section{IAN DONALD INTER-UNIVERSITY SCHOOL OF MEDICAL ULTRASOUND}

Ian Donald (1910-1987) has changed the face of obstetrics and gynecology by the invention of diagnostic ultrasound, in the middle of the 20th century. It is not overstating the fact to say that this innovation has changed the way of thinking of our generation. In recognition of his most significant contribution to the overall development of diagnostic ultrasound, a School of Medical Ultrasound named after Ian Donald was formed in Dubrovnik, Croatia, in 1981 and at present, it has 80 branches worldwide. The objectives of Ian Donald School of Ultrasound are as follows:

1. To promote:

- The science and art of ultrasound scanning

- Research and education in the field of medical ultrasound

- Continuous training in ultrasound

- Facilitate and disseminate the information featured in scientific publications, including the Ian Donald School Journal of Ultrasound in Obstetrics and Gynecology and

- Appropriate counseling of women who receive ultrasound examinations.

2. To provide expert advice to those entering the field of ultrasound.

3. To increase knowledge of methodology for implementing recent ultrasound advances.

4. To contribute to the improvement of teaching standards by the introduction of computer technology and devices for telemedicine.

\section{Basic and Advanced Courses}

This educational program includes basic courses (basic theory and practice), advanced ultrasound education (advanced diagnostic imaging) and fellowship ultrasound education (individual clinical practice). Basic theory includes theory of ultrasound, knowledge of basic science (anatomy, physiology), knowledge of basic art (symmetry, 3 dimensions), study of sophisticated images and is followed by basic practice including live scan demo, hands-on and case studies. Typically, the basic courses include the following objectives: ${ }^{1}$

- Gestational age assessment

- Ultrasound examination in normal pregnancy

- Basic knowledge of color Doppler ultrasound

- Transvaginal sonography

- Normal embryonal and early fetal anatomy

- Ultrasonic assessment of early placentation

- Ultrasonic markers of chromosomopathies

- Pathology of placenta

- Ultrasonic assessment of normal and abnormal fetal growth

- Ultrasound in preterm delivery

- Multiple pregnancy

- Fetal echocardiography

- Prenatal diagnosis

- Counseling a woman when an anomaly is diagnosed

- Prenatal screening in the first and second trimester

- Color Doppler in early pregnancy

- Hemodynamic of embryo

- Utero placental hemodynamic and intervillous blood flow

- Color Doppler in late pregnancy, assessment of arterial blood flow

- Transvaginal examination: PID and benign processes

- The assessment of malignant pelvic processes

- Ectopic pregnancy

- Congenital anomalies: CNS, neck, thorax and abdomen, urinary tract, skeletal abnormalities

- Endometriosis

- Ultrasound in the assessment of female infertility

- Uterine anomalies and hysterosonosalpingography.

\section{Fellowship Program}

Dubrovnik International University (DIU) has developed a specialized fellowship in Ultrasound in Obstetrics and Gynecology. ${ }^{2}$ The study consists of six obligatory and one elective modules with total of 300 hours and 44.9 ECTS. Fellowship programs are one-year courses on a part-time basis. The course can be attended without compromising professional or private commitments because they are organized as six modules over the time of 12 months, every second month, for nine days including two weekends. Upon passing all the written, oral and practical exams and fulfilling 
all the course requirements, attendants are awarded Master degree issued by Dubrovnik International University. They are eligible to continue $\mathrm{PhD}$ study at the same university. The attendants should have a diploma of completed medical education, and a valid obstetrics and gynecology license. After finishing this program, the participants should be capable of:

- Knowing how to use and adjust and being oriented with images produced by transabdominal and transvaginal US.

- Identifying and differentiating between normal and abnormal gynecological US examination.

- Identifying different pathology on pelvic US.

- Performing complete US examination in all trimesters of pregnancy.

- Learning how to write a comprehensive obstetric US report in the 1st, 2nd and 3rd trimesters of pregnancy.

- Performing a 1st trimester ultrasound scan.

- Performing a complete fetal anatomy scan in 2nd trimester of pregnancy.

- Recognizing fetal dysmorphology and knowing the significance of their presence.

- Assessing fetal well-being.

- Knowing how and when to use color Doppler in obstetrics and gynecology ultrasound.

- Witnessing and getting acquainted by the invasive procedures in fetal medicine.

- Witnessing and being acquainted for the 3D/4D US application in obstetrics and gynecology.

Each trainee should complete six modules before being subjected to final examination. Each module is composed of the theoretical part and practical training (scanning demonstration and hands-on training is almost $40 \%$ of the curriculum). Each module delivers 50 hours of training including the theoretical and practical part. Total number of hours allocated is 300 hours. Each candidate is expected to complete his/her log book and present it at the end of each module. A comprehensive end of module exam will be given at the end of each module. After completion of each module, the fellow should present or send via e-mail the certificate proving attendance, which qualifies him/her to take the summative (final) exam. Final exam includes ultrasound skills exam, written essay and theoretical oral exam with committee of three examiners. Detailed structure of the fellowship program is divided into seven modules:

- Module 1: US in gynecology

- Module 2: US in the 1st trimester

- Module 3: Fetal well-being (fetal biometry and fetal growth)

- Module 4: Fetal anatomy — placenta — umbilical cord

- Module 5: Fetal congenital anomalies
- Module 6:3D and Doppler in gynecology and infertility

- Module 7: How to write scientific texts - elective module For details, please refer to the article on 'Obstetrics and Gynecology US Fellowship_Experience of Dubrovnik International University Fellowship Program in Dubai' by Kurjak et al.

\section{ULTRASOUND EDUCATION IN JAPAN}

In Japan, the first Ian Donald ultrasound course was held in 1998 (Fig. 1). Since then, two types of Ian Donald courses have been held: basic and advanced courses (Table 1). Basic ultrasound courses consist of lectures about the basic principles of ultrasound, general and particular knowledge of fetal maternal medicine and imaging. Advanced courses consist of interactive seminars, focusing on special themes, such as first trimester ultrasound scan, prenatal diagnosis, fetal brain, fetal skeletal dysplasia and fetal heart.

Since 2010, Prof K Baba and Japan Society of Maternal and Fetal Medicine conduct on annual basis ultrasound seminars in obstetrics and gynecology for postgraduate physicians and medical staff, such as midwives and examiners.

\section{Ian Donald Basic Ultrasound Courses}

In 1998, the 1st course of Ian Donald School was held by Drs Nakano and Maeda in Fukuoka. This was the first systematic obstetrics and gynecology ultrasound course in Japan. Thereafter, Japanese branch has held basic

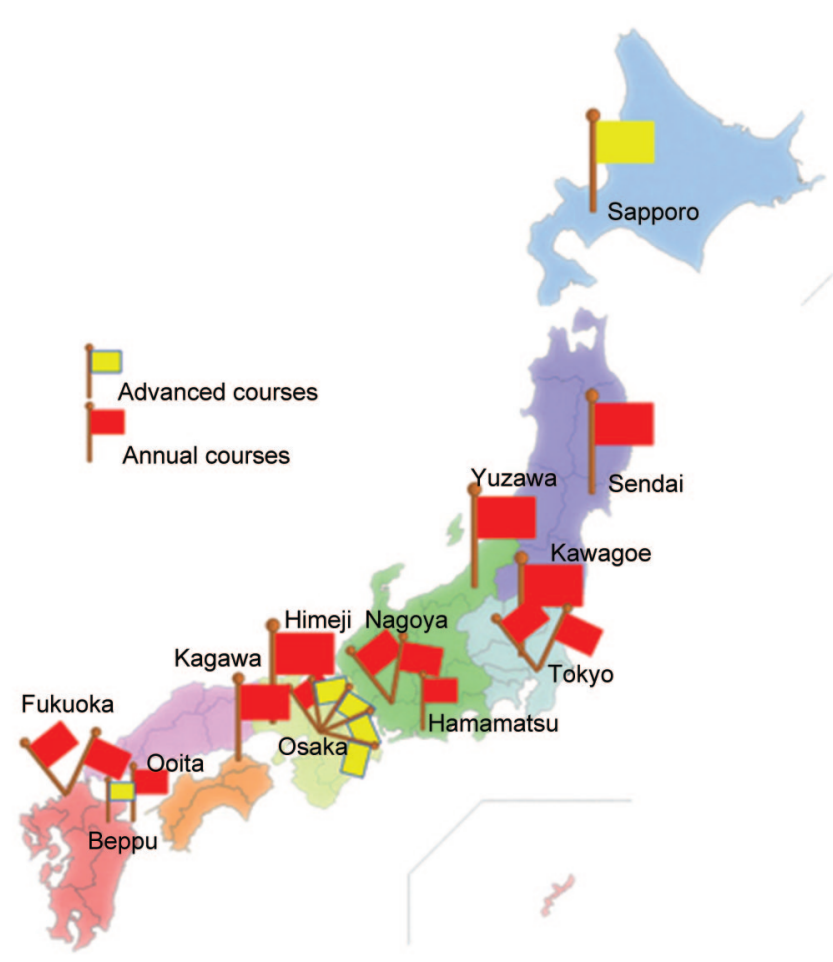

Fig. 1: Japan lan Donald ultrasound courses between 1998 and 2012 


\begin{tabular}{|c|c|c|c|c|}
\hline Year & Place & Organizer & No. of participants & No. of lecturers \\
\hline \multicolumn{5}{|c|}{ Annual courses } \\
\hline 1998 & Fukuoka & H Nakano & 170 & 22 \\
\hline 2000 & Tokyo & H Takeuchi & 200 & 29 \\
\hline 2001 & Yuzawa & Y Chiba & 200 & 31 \\
\hline 2002 & Nagoya & I Kawabata & 220 & 30 \\
\hline 2003 & Sendai & M Okamura & 180 & 27 \\
\hline 2004 & Fukuoka & Y Chiba & 600 & 19 \\
\hline 2005 & Himeji & N Akamatsu & 130 & 21 \\
\hline 2006 & Kagawa & RK Pooh & 107 & 26 \\
\hline 2007 & Tokyo & T Okai & 200 & 16 \\
\hline 2008 & Kawagoe & K Baba & 140 & 20 \\
\hline 2009 & Ooita & S Satoh & 200 & 13 \\
\hline 2010 & Hamamatsu & T Murakoshi & 227 & 20 \\
\hline 2011 & Osaka & RK Pooh & 220 & 24 \\
\hline 2012 & Nagoya & T Sekiya & 293 & 39 \\
\hline \multicolumn{5}{|c|}{ Advanced courses } \\
\hline 2008 & Osaka & RK Pooh & 217 & 19 \\
\hline 2009 & Osaka & RK Pooh & 251 & 26 \\
\hline 2010 & Osaka & RK Pooh & 170 & 11 \\
\hline 2011 & Sapporo & T Yamada & 109 & 15 \\
\hline 2012 & Beppu & J Yoshimatsu & 114 & 18 \\
\hline 2013 & Osaka & H Inoshita & 206 & 20 \\
\hline \multicolumn{5}{|c|}{ Focused practical seminar } \\
\hline 2009 & Osaka & RK Pooh & 35 & 15 \\
\hline
\end{tabular}

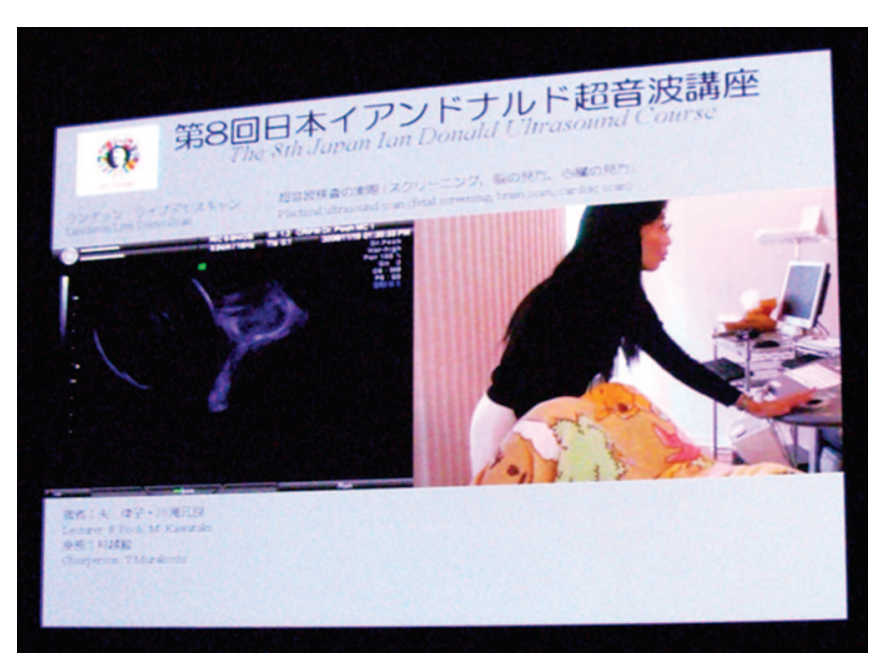

Fig. 2: First live scan demonstration of transvaginal fetal brain scan in 2006

ultrasound courses every year in many places. As only a few educational seminars on medical ultrasound have been held in Japan, the Ian Donald School basic courses have been very useful in providing fruitful opportunity to acquire up-to-date knowledge of clinical ultrasound for obstetrics and gynecology physicians. Dr Kurjak has attended all the annual conferences as well as many other foreign lecturers, such as Drs Chervenak (USA), Timor-Tritsch (USA), ShiJoon Yoo (Canada), Kim Jong (Korea), Jin-Chung Shih
(Taiwan), Kupesic, Zalud, etc. At the time of 8th course in Kagawa, the first trial of live transabdominal/transvaginal scan was performed (Fig. 2).

\section{Ian Donald Advanced Ultrasound Courses}

In January of 2008, the 1st advanced course of Ian Donald in Japan was held in Osaka, organized by Dr Pooh. The main topics of the course were first trimester scan (FTS) and fetal brain. Two hundred seventeen participants attended the course. On the first day, theoretical course on nuchal translucency (NT) and first trimester scan of FMF (Fetal Medicine Foundation) was held. Drs Lau from Hong Kong and Pooh gave 16 lectures on FTS, and Dr Nicolaides gave his passionate lecture from London via video conference. On the second day, 16 Japanese lecturers including Drs Maeda, Shiota, Pooh, pediatric neurologist, pediatric neurosurgeons and genetic counselors gathered and gave special lectures on the fetal brain. Live scan demonstration of fetal brain and basic examination by transabdominal ultrasound were held by Dr Ichizuka, and fetal neurosonography by transvaginal ultrasound was held by Pooh.

In February and March of 2008, two practical courses on the first trimester scan of FMF were held at the CRIFM PMC (International Ian Donald Educational Center) by Dr Pooh. Participants took time for scanning patients to learn how to 


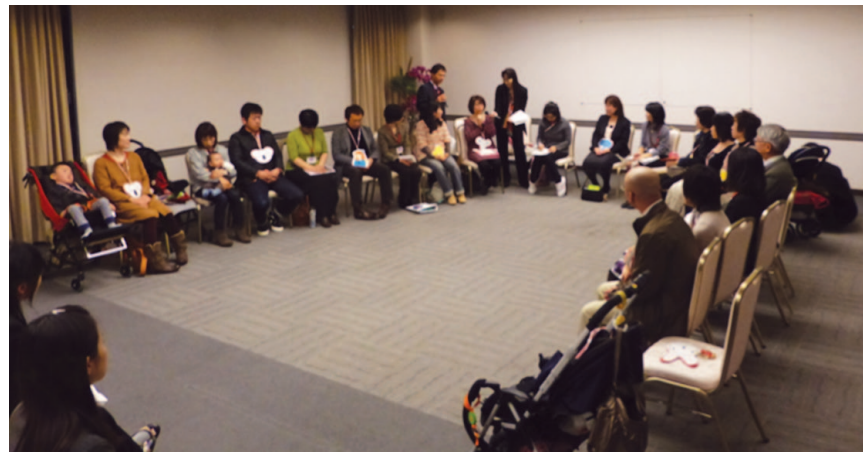

Fig. 3: Eight families who had experienced having disabled child, termination of pregnancy because of severe fetal disease and/or delivery of healthy baby after poor obstetrical history gathered for discussion in precourse event
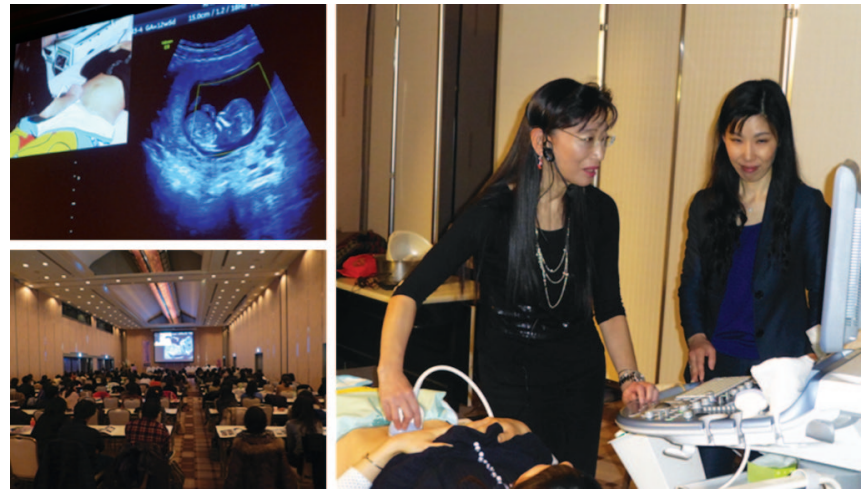

Fig. 4: Hands-on training of transabdominal first trimester scan

demonstrate the accurate cutting section for measurement of nuchal translucency and how to screen for intrauterine growth restricted fetus under the specialists' guidance and instruction.

In 2011, Drs Yamada and Pooh held the 4th advanced course in Sapporo. In 2012, Drs Yoshimatsu and Pooh held the 5th advanced course in Beppu with a special lecturer, Dr Ville from France. In 2013, Drs Inoshita and Pooh held the 6th advanced course in Osaka with a special lecturer, Dr Bianchi from Boston, USA. The theme of the course was 'prenatal diagnosis, for whom, for what, and noninvasive prenatal genetic testing was discussed as one of the topics. As a pre-course event, eight families, who had experienced having disabled child, termination of pregnancy because of severe fetal disease and delivery of healthy baby after poor obstetrical history have gathered for discussion about 'prenatal diagnosis, for whom and for what?' (Fig. 3). Thereafter, live scan session and hands-on session (Fig. 4) as well as lectures were held.

\section{ULTRASOUND EDUCATION AT CRIFM PMC (INTERNATIONAL IAN DONALD EDUCATIONAL CENTER)}

CRIFM PMC is one of the recognized International Ian Donald Educational Centers, where many junior obstetrics

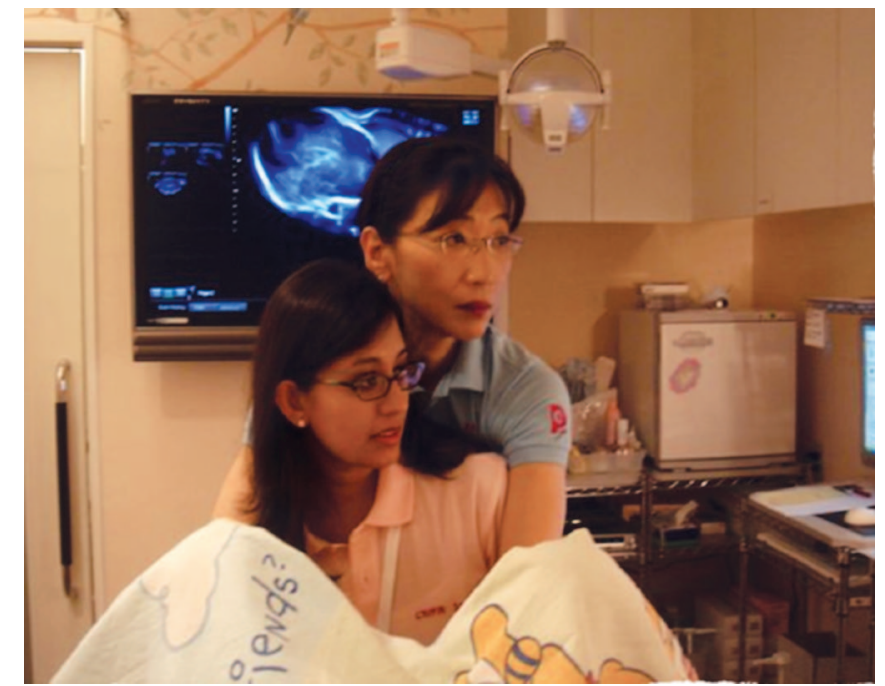

Fig. 5: Transvaginal imaging of fetal brain under supervisor's guidance and assistance at CRIFM PMC (International lan Donald Educational Center)

and gynecology physicians were trained in basic obstetrics and gynecology ultrasound scanning. Trainees are introduced to transvaginal approach for fetal brain scanning under supervisor's assistance and guidance (Fig. 5). Hands-on training is complemented with daily case conference studies using the image database system (Fig. 6).

\section{ULTRASOUND EDUCATION IN EAST ASIAN REGION}

From 2006 China, Indonesia, Hong Kong, Philippines and Vietnam established Ian Donald branches (Table 2) and hold their ultrasound courses successfully (Fig. 7). In 2013, Thailand and Korea joined the big Ian Donald family (Figs 8A and B).

\section{THE FUTURE PERSPECTIVE}

The most important factor which has influenced the changes occurring in education is development of Internet and electronic multimedia techniques. Traditional education as well as contemporary education is supported by informatics technologies in a unique system of flexible education. In order to use the advantages of flexible education, it is necessary to combine different forms of learning.

Indeed, Donald Schools have to reinvent themselves in order to remain relevant to the current generation. The focus in Ian Donald School is on promotion of knowledge augmentation and not on grades. Great learners are the product of great educators. It is hoped that Ian Donald School educators will be true, dedicated 'human amplifiers', who will turn education into a memorable experience. In our newly formed Fellowship Program, upon graduation, student laureates earn a specialist diploma of Ultrasound in Obstetrics and Gynecology, which will allow them to obtain a leadership position in their work place. In Ian 

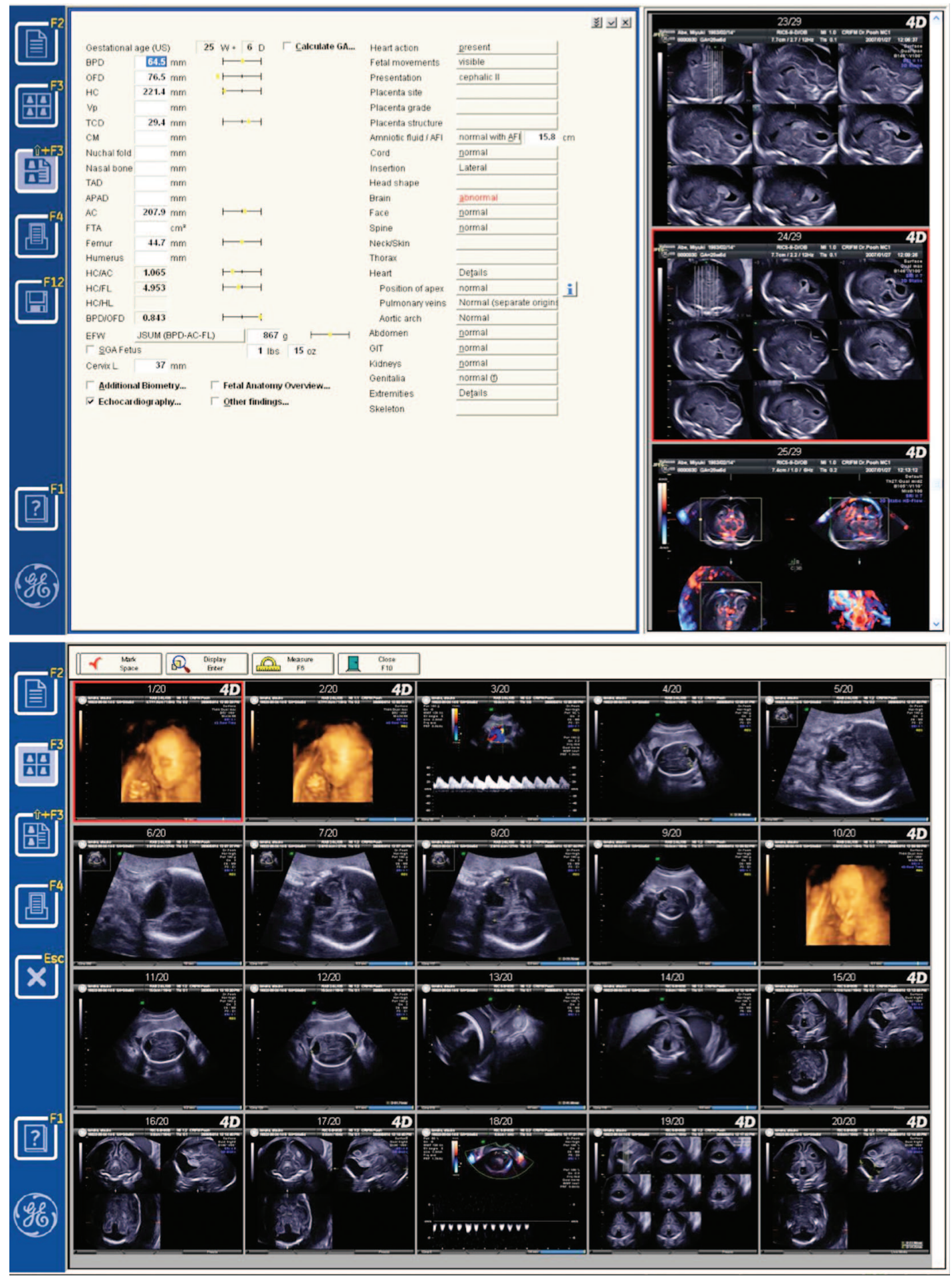

Fig. 6: Case conference study by using image database system

Table 2: Ian Donald school in east Asian region

\begin{tabular}{lll}
\hline 1 st course & Place, country & Organizer \\
\hline 2006 & Jiangsu, China & Tony Duan \\
2008 & Jakarta, Indonesia & Azen Salim \\
2008 & Hong Kong & Tze Kin Lau \\
2010 & Manila, Philippines & Corazon Yabes Almirante \\
2011 & Ho Chi Minh, Vietnam & Ha To Nguyen \\
2013 & Seoul, Korea & Gwang Jun Kim \\
2013 & Bangkok, Thailand & Tuangsit Wataganara \\
\hline
\end{tabular}




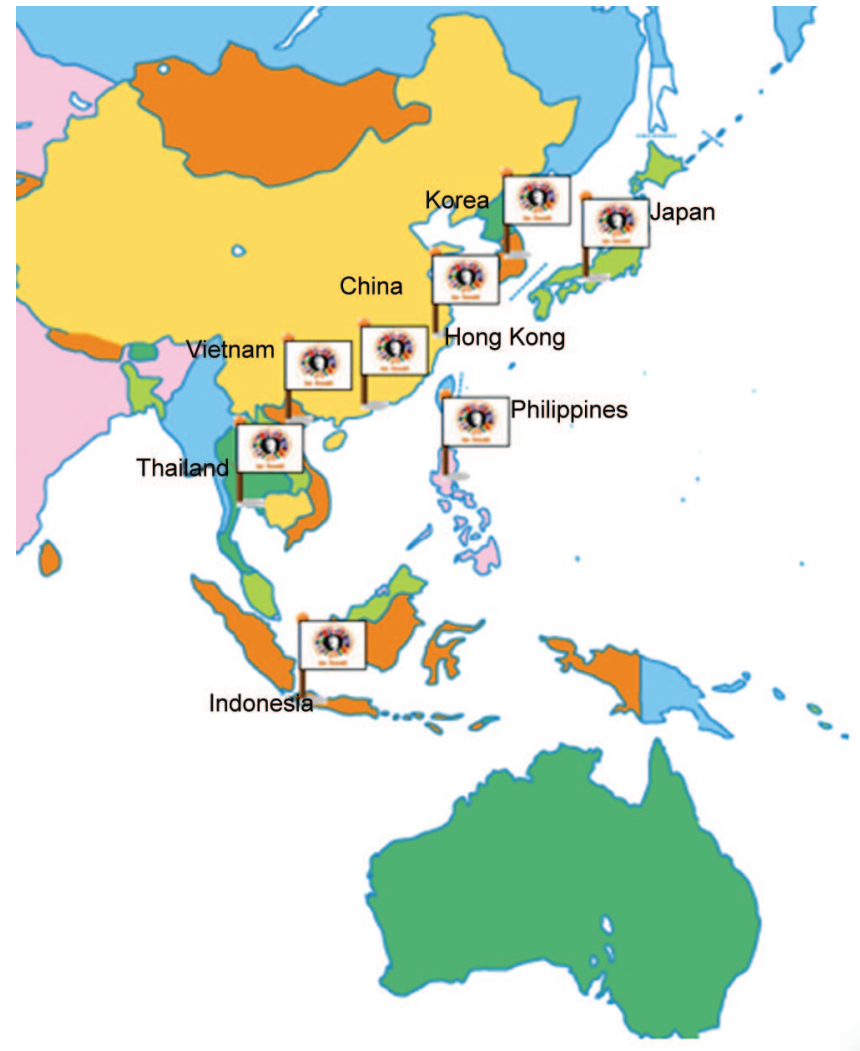

Fig. 7: Ian Donald branches in east Asian region

Donald system, education is driven by innovative thinking, adaptability and worldwide collaboration. Wherever thinking happens, ideas follow, knowledge grows and people discover new ways to unlock their potential. Although in its infancy, the fellowship program has blossomed with its wide acceptability. Undoubtedly, Donald Schools have to reinvent themselves in order to remain attractive to the younger generation as well as stay success story in globalized medicine. With this innovation, we sincerely hope that our school will stay as an internationally recognized brand, representing the future of education as it faces new global challenges and the changing needs of future generations of first class ultrasonic experts.

In Asian region, many physicians and staff are eager to learn basic and novel ultrasound techniques. Ian Donald Inter-University School of Medical Ultrasound provides the
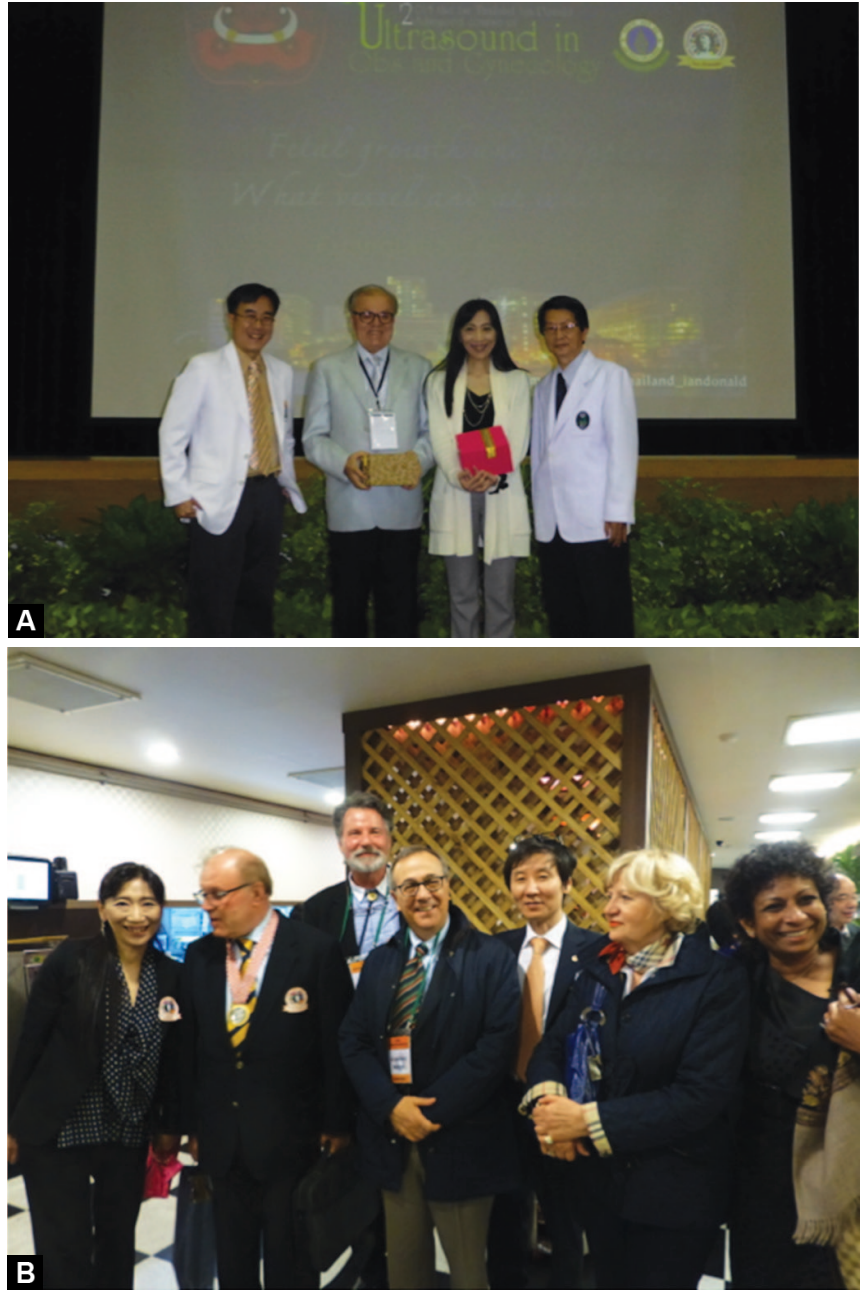

Figs 8A and B: Recent new branches in Thailand $(A)$ and Korea (B) in 2013

most comprehensive, practical and systematic theoretical/ practical courses. It is expected that more branches will be opened up in Asia. Widespread use of distance online education will enable efficient delivery of a cohesive and innovative curriculum of the future.

\section{REFERENCES}

1. Website of Ian Donald Inter-University School of Medical Ultrasound. Available at: http://www.iandonaldschool.org.

2. Website of Dubrovnik International University. Available at: http://www.diu.hr. 